\title{
Effective Utilization of Carbon Nanocoil-supported PtRu Anode Catalyst by Applying Anode Microporous Layer for Improved Direct Methanol Fuel Cell Performance
}

\section{Yoshiaki SHIMIZU, ${ }^{a}$ Yoshiyuki SUDA, ${ }^{a}, *$ Hirofumi TAKIKAWA, ${ }^{a}$ Hitoshi UE, ${ }^{\mathrm{b}}$ Kazuki SHIMIZU, ${ }^{\mathrm{c}}$ and Yoshito UMEDA ${ }^{\mathrm{d}}$}

\author{
a Department of Electrical and Electronic Information Engineering, Toyohashi University of Technology, \\ 1-1 Hibarigaoka, Tempaku, Toyohashi, Aichi 441-8580, Japan \\ b Fuji Research Laboratory, Tokai Carbon Co., Ltd., 394-1 Subashiri, Oyama, Sunto, Shizuoka 410-1431, Japan \\ c Shonan Plastic Mfg. Co., Ltd., 31-27 Daikan, Hiratsuka, Kanagawa 254-0807, Japan \\ d Corporate Research Department, Toho Gas Co., Ltd., Nagoya, Aichi 456-8511, Japan
}

* Corresponding author: suda@ee.tut.ac.jp

\begin{abstract}
The application of a microporous layer (MPL) between the gas diffusion layer and the catalyst layer (CL) plays a crucial role in the performance of the direct methanol fuel cell (DMFC). To this end, this study investigates the effects of carbon loading and the nature of the carbon material used in the anode MPL on the performance of DMFC using transmission and scanning electron microscopy, polarization technique, and electrochemical impedance spectroscopy (EIS). DMFC was indigenously fabricated using $30 \mathrm{wt} \%$ PtRu catalyst supported on carbon nanocoil and commercial Pt catalyst as the anode CL and the cathode CL, respectively. Carbon nanoballoon (CNB) and Vulcan $\mathrm{XC}-72 \mathrm{R}$ (Vulcan) were used as the anode MPL. According to polarization studies, a membrane electrode assembly (MEA) with CNB and Vulcan MPLs (loading of $1.5 \mathrm{mg} \mathrm{cm}^{-2}$ ) shows higher power density. This is 1.3 and 1.8 times higher than that without the anode MPL when methanol concentration was $0.5 \mathrm{M}\left(\mathrm{M}=\mathrm{mol} \mathrm{dm}^{-3}\right)$, respectively. Electrochemical impedance spectra (EIS) results indicate that the MEAs with the anode MPLs have lower highfrequency resistance and charge transfer resistance when compared to those without the anode MPL. Thus, it can be realized that the anode MPL plays a significant role in the effective utilization of CNC-supported PtRu anode catalyst, thereby improving DMFC performance.
\end{abstract}

(C) The Electrochemical Society of Japan, All rights reserved.

Keywords : Microporous Layer, Carbon Nanocoil, Carbon Nanoballoon, Carbon Loading

\section{Introduction}

Direct methanol fuel cell (DMFC) is a promising energy source for portable and automotive applications, mainly due to their low operating temperature, direct use of liquid fuel, and simple structure without the stringent need for a reformer. ${ }^{1-3}$ Nevertheless, issues such as water management and methanol crossover still limit the widespread commercial application of DMFC. ${ }^{4-8}$ In particular, the permeation of methanol from the anode to the cathode presents a negative effect on the open circuit voltage, fuel efficiency utilization, and its overall performance.

To this end, several studies have been conducted over the past decade for the effective mitigation of both water and methanol crossover in DMFC. ${ }^{6-18}$ Liu et al. ${ }^{19}$ reported the design of a membrane electrode assembly (MEA) that consisted of a thin membrane and a backing layer coated with a highly hydrophobic microporous layer (MPL), in order to reduce the rates of both the water and methanol crossover. The MPL, in particular, plays an important role in the water management of DMFC. It significantly contributes to the reduction of water crossover through the membrane, thereby improving the overall performance of the DMFC. ${ }^{17,18,20}$

In our previous study, we analyzed the use of carbon nanocoils (CNCs) as a catalyst support in DMFC. ${ }^{21}$ Due to their threedimensional structure, $\mathrm{CNC}$ is considered to be a unique support material for electrocatalyst materials. By using CNCs in the DMFC cathode, the diffusion of fuel and gas, and the removal of reaction products became considerably smoother. Consequently, the DMFC with CNCs showed higher power density when compared to other carbon nanomaterials, such as Vulcan XC-72R (Vulcan) and arc black (AcB). In addition, we performed electrochemical studies of the PtRu catalysts as an anode catalyst supported on carbon nanomaterials for methanol oxidation using cyclic voltammetry. Results indicate higher catalytic activity of the PtRu catalyst supported on $\mathrm{CNC}$ when compared to those on $\mathrm{AcB}$ and Vulcan. However, the use of CNCs in the anode of DMFC did not prevent the permeation of methanol across the membrane, and hence resulted in poor DMFC performance. Therefore, to utilize the advantages of CNC as an anode catalyst support, we applied the anode MPL to DMFC for improving the efficiency of utilization of the CNC-supported PtRu catalyst. To the best of our knowledge, there are no studies reported so far on the DMFC performance of a MEA with MPL as the anode using CNCs in the anode catalyst layer (CL). The anode MPL is expected to play a crucial role in preventing the permeation of methanol across CNCs in the anode CL. Therefore, in this study, $30 \mathrm{wt} \% \mathrm{PtRu}$ (atomic ratio 1:1) supported CNC was used as the anode CL. Carbon nanoballoon (CNB) and Vulcan were used as the anode MPL materials. CNB is a unique material because of its hollow structure and high electrical conductivity, while Vulcan has a high surface area and high electrical conductivity. Furthermore, we investigated the optimization of carbon loading and carbon type in the anode MPL.

\section{Experimental}

\subsection{Synthesis of carbon nanomaterials}

$\mathrm{CNCs}$ were synthesized using an automatic chemical vapor deposition system with a consecutive substrate transfer mechan- 

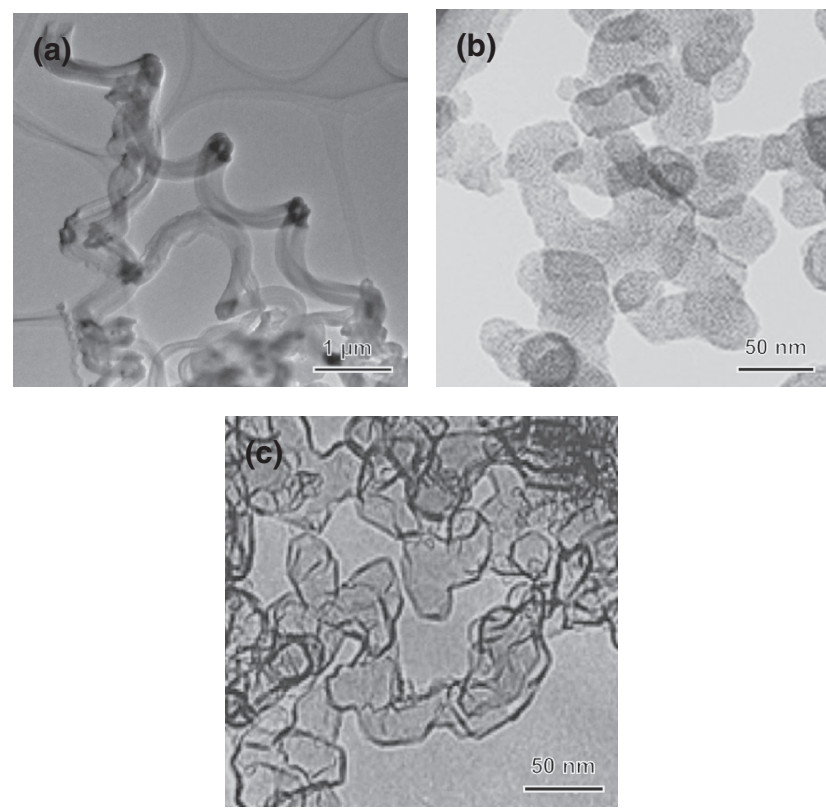

Figure 1. TEM images of carbon nanomaterials: (a) CNC, (b) $\mathrm{AcB}$, and (c) CNB.

ism. ${ }^{22,23}$ In the typical process, $0.2 \mathrm{~mL}$ Fe-Sn catalytic solution was dropped onto a graphite substrate of diameter $100 \mathrm{~mm}$. Subsequently, the substrate was calcined at $350^{\circ} \mathrm{C}$ for $8 \mathrm{~min}$. The flow rate of the $\mathrm{C}_{2} \mathrm{H}_{2}$ source gas was $0.35 \mathrm{~L} \mathrm{~min}^{-1}$ and that of the $\mathrm{N}_{2}$ dilution gas was $1.4 \mathrm{~L} \mathrm{~min}^{-1}$. CNCs were synthesized at $780^{\circ} \mathrm{C}$. Figure 1 (a) shows the transmission electron microscopy (TEM) image of the $\mathrm{CNC}$ thus obtained. As seen in the figure, the fiber diameter of the CNCs is $\sim 300 \mathrm{~nm}$, the coil diameter is $\sim 1000 \mathrm{~nm}$, and the coil length is $\sim 10 \mu \mathrm{m}$. The purity of the as-grown CNC sample, as evaluated using scanning electron microscopy (SEM), was $\sim 80 \%$. The impurities in the sample were typically carbon nanofibers (CNFs) and carbonaceous materials. The CNC thus obtained in this study was used as the catalyst support in the anode CL.

$\mathrm{AcB}$ was synthesized using the twin-torch arc discharge apparatus developed in our laboratory. ${ }^{24}$ The discharge chamber consisted of two graphite rod electrodes mounted at $80^{\circ} \mathrm{C}$ in an $80-\mathrm{kPa} \mathrm{N}_{2}$ atmosphere, which generated arc discharge with an AC current of $200 \mathrm{~A}$. The $\mathrm{N}_{2}$ gas flow rate was maintained as $20 \mathrm{~L} \mathrm{~min}^{-1}$. Figure 1(b) shows the TEM image of the AcB prepared in this study. As seen in the figure, $\mathrm{AcB}$ comprises spherical particles of diameter $50 \mathrm{~nm}$, the surface structure of which is dissimilar from dahlia, making it different from that of carbon nanohorns. ${ }^{25}$

Subsequently, CNB was obtained by heating AcB in a Tammann oven in Ar gas at $2000^{\circ} \mathrm{C} \sim$ for $2 \mathrm{~h}$. The TEM image of the CNB thus obtained is shown in Fig. 1(c). CNB has a high electrical conductivity and consists of hollow particles. The number of graphitic layers in CNB is found to increase, resulting in a thicker shell, with increase in the heating temperature. ${ }^{26}$ In this study, we used an optimum temperature of $2600^{\circ} \mathrm{C}$ for preparing the $\mathrm{CNB}$.

Commercially available Vulcan XC-72R (Cabot Corp., Boston, MA, USA) was used as the Vulcan sample.

The electrical resistivites of CNB and Vulcan were obtained as follows: $300 \mathrm{mg}$ of each carbon nanomaterial was taken in a plastic tube of cross-section $1.5 \mathrm{~cm}^{2}$ and pressed in a pressing machine at $1.0 \mathrm{MPa}$. The electrical conductivity of $\mathrm{CNB}$ and Vulcan was $1.8 \mathrm{~S} \mathrm{~cm}^{-1}$ and $2.1 \mathrm{~S} \mathrm{~cm}^{-1}$, respectively. ${ }^{25}$

\subsection{Preparation of the catalyst}

We prepared PtRu catalysts for the anode of DMFC. The PtRu catalysts were supported on $\mathrm{CNC}$ by reduction using sodium borohydride $\left(\mathrm{NaBH}_{4}\right){ }^{27}$ Hydrogen hexachloroplatinate (IV) hexa- hydrate $\left(\mathrm{H}_{2} \mathrm{PtCl}_{6} \cdot 6 \mathrm{H}_{2} \mathrm{O}\right)$ and ruthenium trichloride $\left(\mathrm{RuCl}_{3}\right)$ were used as the $\mathrm{Pt}$ and $\mathrm{Ru}$ precursors, respectively. The molar ratio of $\mathrm{Pt}$ and $\mathrm{Ru}$ was set at 1:1, with the optimum precursor loading concentration of $30 \mathrm{wt} \%$, based on the results obtained in our previous study. Meanwhile, 50wt\% Pt/C (Tanaka Kikinzoku International K.K., Tokyo, Japan) was used for the cathode catalyst.

\subsection{Preparation of the anode MPL}

Commercial carbon papers TGP-H-090 (Toray, Tokyo, Japan) of thickness $280 \mu \mathrm{m}$ and SGL24-BC (Toray, Tokyo, Japan) of thickness $235 \mu \mathrm{m}$ were used as the anode and cathode gas diffusion layers (GDL), respectively. In the typical process, anode MPL was prepared via dispersing $\mathrm{CNB}$ or Vulcan in isopropyl alcohol containing polytetrafluoroethylene (PTFE). The weight ratio of PTFE to the carbon nanomaterials was maintained at $1: 1$. Subsequently, the mixed ink was dispersed by sonication for $30 \mathrm{~min}$. The MPL solution was directly sprayed onto the anode GDL to fabricate the anode MPL. According to the abovementioned procedure, we prepared anode MPLs with different carbon loading, namely, $0,1.0,1.5$, and $2.0 \mathrm{mg} \mathrm{cm}^{-2}$ for CNB and $1.5 \mathrm{mg} \mathrm{cm}^{-2}$ for Vulcan.

\subsection{Preparation of MEA}

Nafion ${ }^{\circledR} 115$ membrane (Du Pont, K.K., Tokyo, Japan) was used as an electrolyte membrane. The membranes were cleaned several times with de-ionized water, hydrogen peroxide solution, and sulfuric acid. The following procedure was adopted for the fabrication of anode and cathode CLs: the anode and cathode inks were prepared by mixing $30 \mathrm{wt} \% \mathrm{PtRu} / \mathrm{CNC}$ as the anode catalyst and $50 \mathrm{wt} \% \mathrm{Pt} / \mathrm{C}$ as the cathode catalyst with $5 \mathrm{wt} \%$ Nafion solution in 1-propanol and isopropyl alcohols. The weight ratio of ionomer to carbon was $1: 1$. Subsequently, the inks were uniformly sprayed onto the PTFE substrate. The substrates were then hot-pressed on both sides of the electrolyte membrane at the pressure of $15 \mathrm{MPa}$ at $130^{\circ} \mathrm{C}$ for $10 \mathrm{~min}$. The amount of $\mathrm{Pt}$ in the anode and cathode CLs was maintained at $0.3 \mathrm{mg} \mathrm{cm}^{-2}$. The active area of the MEA was $8.41 \mathrm{~cm}^{-2}$. The MEA thus obtained was mounted in the DMFC (Japan Automobile Research Institute, Tsukuba, Japan). To further test the performance of the DMFC, $0.5 \mathrm{M}\left(\mathrm{M}=\mathrm{moldm}^{-3}\right)$ of methanol was supplied to the anode at a flow rate of $0.1 \mathrm{~mL} \mathrm{~s}^{-1}$, and dry air was supplied to the cathode at a flow rate of $5 \mathrm{~mL} \mathrm{~s}^{-1}$. The DMFC was operated at $60^{\circ} \mathrm{C}$. The polarization characteristics and electrochemical impedance spectra (EIS) of the DMFC were measured using a fuel cell impedance meter (Kikusui Electronics Corp., Yokohama, Japan, KFM2030). For all the impedance measurements, the measured frequencies were set in the range of $10 \mathrm{kHz}$ to $0.1 \mathrm{~Hz}$. The MEAs with different anode MPLs, as shown in Table 1, were tested to clarify the effects of CNB loading and the nature of carbon material on the performance of DMFC. The surface morphologies of the carbon nanomaterials and the anode MPLs were examined using TEM (JEM-2100F, JEOL, Tokyo, Japan) and SEM (S-4500 II and SU8000, Hitachi High-Technologies Corp., Tokyo, Japan), respectively.

\section{Results and Discussion}

\subsection{Morphology of the anode MPL}

In general, carbon loading in the anode MPL is a significant factor influencing the performance of the DMFC. Therefore, in this study, we investigated carbon loading to optimize the performance of DMFC. The SEM image shown in Fig. 2 reveals the surface morphology of the anode MPLs with different CNB loadings of 0 , $1.0,1.5,2.0 \mathrm{mg} \mathrm{cm}^{-2}$ and Vulcan loading of $1.5 \mathrm{mg} \mathrm{cm}^{-2}$ on the anode GDL. As shown in Fig. 2(a), the morphology of anode GDL without the anode MPL is a microscopically complex fibrous structure, with various pore size distributions ranging from a few microns to tens of microns. Conversely, the SEM images of the 
Table 1. Summary of anode MPLs with different CNB and Vulcan loadings and their corresponding power densities.

\begin{tabular}{cccc}
\hline & Anode & Cathode & Power density $/ \mathrm{mW} \mathrm{cm}^{-2}$ \\
\hline Methanol concentration & & & $0.5 \mathrm{M}$ \\
\hline MPL-1 & Without the MPL & Commercial SGL-24BC & 12.1 \\
MPL-2 & $1.0 \mathrm{mg} \mathrm{cm}^{-2} \mathrm{CNB}$ & Commercial SGL-24BC & 13.5 \\
MPL-3 & $1.5 \mathrm{mg} \mathrm{cm}^{-2} \mathrm{CNB}$ & Commercial SGL-24BC & 15.3 \\
MPL-4 & $2.0 \mathrm{mg} \mathrm{cm}^{-2} \mathrm{CNB}$ & Commercial SGL-24BC & 13.6 \\
MPL-5 & $1.5 \mathrm{mg} \mathrm{cm}^{-2}$ Vulcan & Commercial SGL-24BC & 22.8 \\
\hline
\end{tabular}
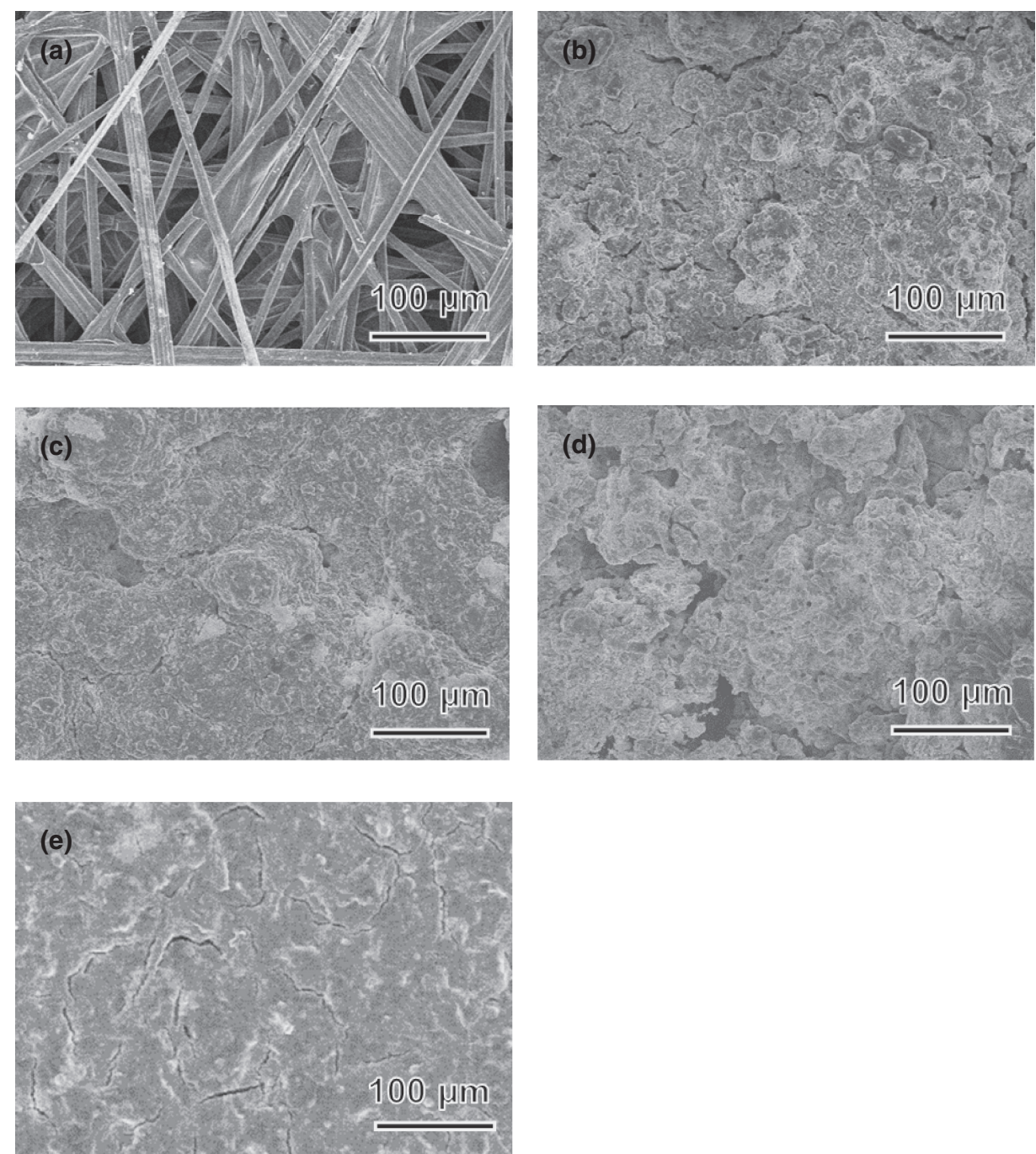

Figure 2. SEM images showing the surface morphology of MPLs in different anode MPLs: (a) without MPL, CNB loadings of (b) $1.0 \mathrm{mg} \mathrm{cm}^{-2}$, (c) $1.5 \mathrm{mg} \mathrm{cm}^{-2}$ (d) $2.0 \mathrm{mg} \mathrm{cm}^{-2}$, and Vulcan loadings of (e) $1.5 \mathrm{mg} \mathrm{cm}^{-2}$.

anode MPLs [Figs. 2(b)-(e)] show a much smaller pore size with a few mud cracks. As seen in the figure, some smaller-sized cracks and voids are scattered on the surface of the anode MPLs, while fewer cracks and voids were observed on the surface of the anode MPLs with $\mathrm{CNB}$ and Vulcan loadings of $1.5 \mathrm{mg} \mathrm{cm}^{-2}$. The microstructure of the anode MPL with CNB loading of $2.0 \mathrm{mg} \mathrm{cm}^{-2}$ was characterized by a large number of surface cracks and pores. The presence of large cracks and voids in the anode MPL led to poor electrical conductivity of GDL, as explained in Section 3.3. Furthermore, the large cracks also increased the contact resistance between the anode MPL and CL. Overall, the performance of DMFC could be attributed to its anode MPL morphology with cracks and pores.

\subsection{Optimization of carbon loading in the MPL}

The graphs shown in Fig. 3 correspond to the cell polarization and power density of DMFCs with different CNB loadings and Vulcan loading of $1.5 \mathrm{mg} \mathrm{cm}^{-2}$ in the anode MPL. During the performance testing, $0.5 \mathrm{M}$ methanol was supplied to the anode at a flow rate of $0.1 \mathrm{~mL} \mathrm{~s}^{-1}$, and dry air was supplied to the cathode at a flow rate of $5 \mathrm{~mL} \mathrm{~s}^{-1}$. In case of the anode MPL with a CNB loading of $1.5 \mathrm{mg} \mathrm{cm}^{-2}$, the DMFC exhibited higher power density $\left(15.3 \mathrm{~mW} \mathrm{~cm}^{-2}\right)$ when compared to the MEA without the anode MPL $\left(12.1 \mathrm{~mW} \mathrm{~cm}^{-2}\right)$. This result indicates that the surface morphology of the anode MPL with lesser number of cracks effectively reduces the methanol permeation and water crossover. ${ }^{20,28-32}$ However, the anode MPL with CNB loading of $2.0 \mathrm{mg} \mathrm{cm}^{-2}$ 

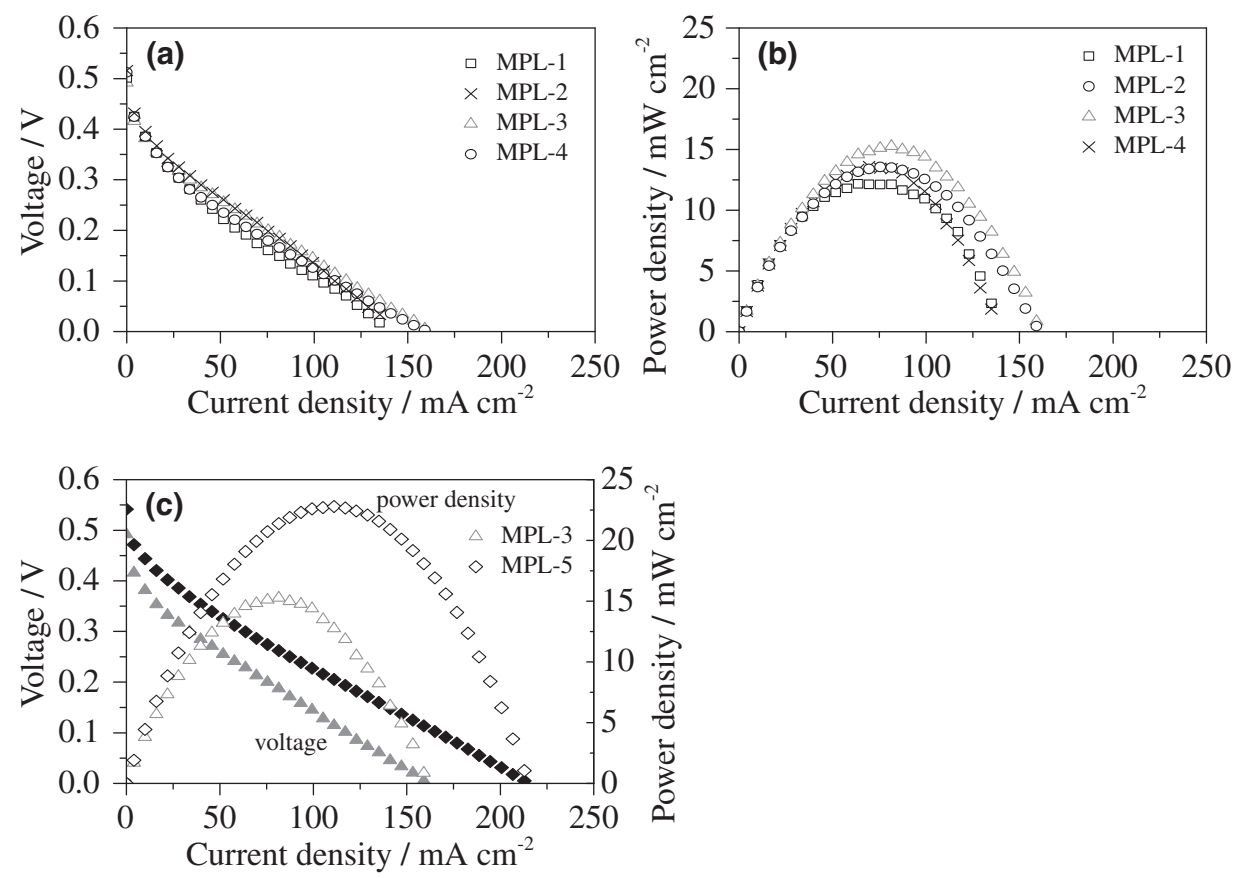

Figure 3. Cell polarization and power density curves of DMFCs with different anode MPLs.

exhibited lower power density. This could be attributed to excess carbon loading, which increased the cracks and pores on the surface of the anode MPL. Such conditions could lead to an increase in the mass transport resistance, the contact resistance between the anode MPL and CL, and the poor conduction of electrons.

In the case of DMFCs with anode MPL comprising various Vulcan loadings in the $0.5-2.5 \mathrm{mg} \mathrm{cm}^{-2}$ range, the highest power density was observed for the DMFC with a Vulcan loading of $1.5 \mathrm{mg} \mathrm{cm}^{-2}$. The graphs shown in Fig. 3(c) indicate the cell polarization and power density of DMFCs with different carbon types in the anode MPLs. The anode MPL with a Vulcan loading of $1.5 \mathrm{mg} \mathrm{cm}^{-2}$ exhibited higher power density $\left(22.8 \mathrm{~mW} \mathrm{~cm}^{-2}\right)$ when compared with the anode MPL with CNB loading of $1.5 \mathrm{mg} \mathrm{cm}^{-2}$ $\left(15.3 \mathrm{~mW} \mathrm{~cm}^{-2}\right)$. These results indicate that the carbon nanomaterials as MPL with high electrical conductivity significantly contributed to the improvement of the DMFC performance.

\subsection{EIS measurement}

Figure 4 shows the EIS results for the MEAs with various types of the anode MPLs. During the test, $0.5 \mathrm{M}$ methanol was fed to the anode at a rate of $0.1 \mathrm{~mL} \mathrm{~s}^{-1}$, and dry air was fed to the cathode at a rate of $5 \mathrm{~mL} \mathrm{~s}^{-1}$. The MEAs with the anode MPLs, except the anode MPL with a CNB loading of $2.0 \mathrm{mg} \mathrm{cm}^{-2}$, exhibited lower highfrequency resistance and lower charge transfer resistance when compared with the MEA without the anode MPL. This result shows that the anode MPL with adequate CNB and Vulcan loadings can promote the conduction of electrons between the anode MPL and CL. Moreover, the MEAs with the anode MPL presented lower impedance as the anode MPL effectively reduced the contact resistance of the electrode. ${ }^{28,29,33-37}$

\section{Conclusion}

In summary, we have investigated the effect of using anode MPL on the performance of DMFC. According to polarization studies, a MEA with CNB and Vulcan MPLs (loading of $1.5 \mathrm{mg} \mathrm{cm}^{-2}$ ) shows higher power density. This is 1.3 and 1.8 times higher than that without the anode MPL when methanol concentration was $0.5 \mathrm{M}$, respectively. The EIS results indicated that the MEA with the anode MPL promoted the conduction of electrons between the anode MPL

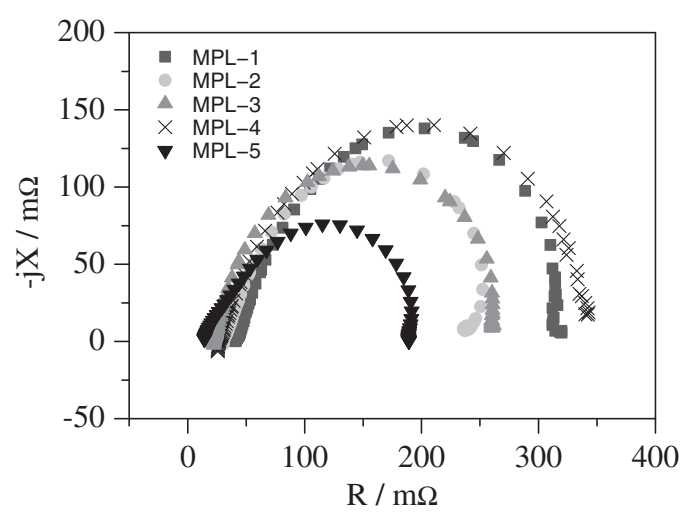

Figure 4. EIS of DMFCs with different anode MPLs.

and the anode $\mathrm{CL}$, and also lowered the high-frequency resistance and charge transfer resistance. These results imply that an optimum carbon loading in the anode MPL is beneficial to improve the effective utilization of CNC-supported PtRu catalyst, thereby taking complete advantage of CNC in DMFC.

\section{Acknowledgment}

This work has been partly supported by the EIIRIS Project from Toyohashi University of Technology (TUT); JSPS KAKENHI Grant Number 24360108 and 25630110.

\section{References}

1. J. S. Yi and T. V. Nguyen, J. Electrochem. Soc., 145, 1149 (1998).

2. S. H. Ge and B. L. Yi, J. Power Sources, 124, 1 (2003).

3. C. K. Dyer, J. Power Sources, 106, 31 (2002).

4. V. Gogel, T. Frey, Z. Yongsheng, K. A. Friedrich, L. Jörissen, and J. Garche, J. Power Sources, 127, 172 (2004).

5. H. Yang, T. S. Zhao, and Q. Ye, J. Power Sources, 139, 79 (2005).

6. A. Blum, T. Duvdevani, M. Philosoph, N. Rudoy, and E. Peled, J. Power Sources, 117, 22 (2003)

7. S. K. Kamarudin, W. R. W. Daud, S. L. Ho, and U. A. Hasran, J. Power Sources, 163, 743 (2007).

8. R. Chen, T. S. Zhao, and J. G. Liu, J. Power Sources, 157, 351 (2006) 
9. G. Q. Lu and C. Y. Wang, J. Power Sources, 134, 33 (2004).

10. H. Kim, J. Oh, J. Kim, and H. Chang, J. Power Sources, 162, 497 (2006)

11. K. Y. Song, H. K. Lee, and H. T. Kim, Electrochim. Acta, 53, 637 (2007).

12. T. Mennola, M. Noponen, T. Kallio, M. Mikkola, and T. Hottinen, J. Appl. Electrochem., 34, 31 (2004)

13. B. S. Pivovar, Polymer, 47, 4194 (2006).

14. T. Schults and K. Sundmacher, J. Membr. Sci., 276, 272 (2006).

15. S. U. Jeong, E. A. Cho, H. J. Kim, T. H. Lim, I. H. Oh, and S. H. Kim, J. Power Sources, 159, 1089 (2006)

16. G. Jewett, Z. Guo, and A. Faghri, J. Power Sources, 168, 434 (2007).

17. C. Xu and T. S. Zhao, J. Power Sources, 168, 143 (2007).

18. C. Xu, T. S. Zhao, and Y. L. He, J. Power Sources, 171, 268 (2007).

19. F. Liu, G. Lu, and C. Y. Wang, J. Electrochem. Soc., 153, A543 (2006)

20. F. Liu and C.-Y. Wang, Electrochim. Acta, 53, 5517 (2008).

21. Y. Suda, S. Kaida, M. Ozaki, Y. Shimizu, Y. Okabe, H. Tanoue, H. Takikawa, H. Ue, and K. Shimizu, AIP Conf. Proc., 1585, 77 (2014).

22. M. Yokota, Y. Suda, H. Takikawa, H. Ue, K. Shimizu, and Y. Umeda, J. Nanosci. Nanotechnol., 11, 2344 (2011).

23. Y. Hosokawa, H. Shinki, Y. Shinohara, M. Yokota, H. Takikawa, T. Ina, F. Okada, Y. Fujimura, T. Yamaura, S. Itoh, K. Miura, and K. Yoshikawa, Res. Lett. Mater. Sci., 2007, 59167 (2007)

24. T. Ikeda, S. Kaida, T. Satou, Y. Suda, H. Takikawa, H. Tanoue, S. Oke, H. Ue, T.
Okawa, N. Aoyagi, and K. Shimizu, Jpn. J. Appl. Phys., 50, $01 \mathrm{AF} 13$ (2011).

25. T. Yoshitake, Y. Shimakawa, S. Kuroshima, H. Kimura, T. Ichihashi, Y. Kubo, D. Kasuya, K. Takahashi, F. Kokai, M. Yudasaka, and S. Iijima, Physica B, 323, 124 (2002).

26. H. Niwa, K. Higashi, K. Shinohara, H. Takikawa, T. Sakakibara, K. Yoshikawa, K. Miura, S. Ito, and T. Yamaura, Smart Process. Technol., 1, 57 (2006)

27. M. Hyun, S. Kim, B. Lee, D. Peck, Y. Shul, and D. Jung, Catal. Today, 132, 138 (2008).

28. J. Zhang, G. P. Yin, Q. Z. Lai, and Z. B. Wang, J. Power Sources, 168, 453 (2007).

29. J.-Y. Park, J.-H. Lee, S. K. Kang, J.-H. Sauk, and I. Song, J. Power Sources, 178, 181 (2008).

30. N. Wan, Z. Mao, C. Wang, and G. Wang, J. Power Sources, 163, 725 (2007).

31. T. S. Zhao, C. Xu, R. Chen, and W. W. Yang, Prog. Energy Combust. Sci., 35, 275 (2009).

32. Q. X. Wu, T. S. Zhao, R. Chen, and W. W. Yang, J. Power Sources, 191, 304 (2009).

33. Z. Qi and A. Kaufman, J. Power Sources, 109, 38 (2002).

34. J. H. Nam and M. Kaviany, J. Heat Mass Transfer, 46, 4595 (2003).

35. U. Pasaogullari and C.-Y. Wang, Electrochim. Acta, 49, 4359 (2004).

36. G.-G. Park, Y.-J. Sohn, T.-H. Yang, Y.-G. Yoon, W.-Y. Lee, and C.-S. Kim, J. Power Sources, 131, 182 (2004).

37. S. H. Yang, C. Y. Chen, and W. J. Wang, J. Power Sources, 195, 3536 (2010). 